\title{
Validity and reliability of the Structured Clinical Interview for the Trauma and Loss Spectrum (SCI-TALS)
}

Liliana Dell'Osso', M Katherine Shear ${ }^{2}$, Claudia Carmassi*1, Paola Rucci ${ }^{1,3}$, Jack D Maser ${ }^{4}$, Ellen Frank ${ }^{3}$, Jean Endicott ${ }^{2}$, Liliana Lorettu ${ }^{5}$, A Carlo Altamura ${ }^{6}$, Bernardo Carpiniello ${ }^{7}$, Francesco Perris ${ }^{8}$, Ciro Conversano ${ }^{1}$, Antonio Ciapparelli ${ }^{1}$, Marina Carlini ${ }^{1}$, Nannina Sarno ${ }^{1}$ and Giovanni B Cassano ${ }^{1}$

Address: ${ }^{1}$ Department of Psychiatry, Neurobiology, Pharmacology and Biotechnologies, University of Pisa, Italy, ${ }^{2}$ Columbia University, New York, USA, ${ }^{3}$ Western Psychiatric Institute and Clinic, University of Pittsburgh, USA, ${ }^{4}$ Department of Psychiatry, University of California, San Diego, USA, ${ }^{5}$ Clinic of Psychiatry, University of Sassari, Italy, ${ }^{6}$ Department of Psychiatry, University of Milan, Italy, ${ }^{7}$ Department of Public Health-Section of Psychiatry, University of Cagliari, Italy and ${ }^{8}$ Department of Psychiatry, University of Naples, Italy

Email: Liliana Dell'Osso - ldelloss@psico.med.unipi.it; M Katherine Shear - ks2394@columbia.edu; Claudia Carmassi* - ccarmassi@gmail.com; Paola Rucci - rucci.paola@tiscali.it; Jack D Maser - jmaser@ucsd.edu; Ellen Frank - FrankE@upmc.edu; Jean Endicott - je10@columbia.edu; Liliana Lorettu - clinpsic@uniss.it; Carlo A Altamura - c.altamura@hsacco.it; Bernardo Carpiniello - bcarpini@iol.it;

Francesco Perris - francerscoperris@hotmail.com; Ciro Conversano - psicologiaapplicata@gmail.com; Antonio Ciapparelli - a.ciapparelli@aopisa.toscana.it; Marina Carlini - marinacarlini@libero.it; Nannina Sarno - nanninasarno@yahoo.it;

Giovanni B Cassano - g.b.cassano@med.unipi.it

* Corresponding author

Published: 28 January 2008

Clinical Practice and Epidemiology in Mental Health 2008, 4:2 doi:10.1 186/1745-0179-4-

2

This article is available from: http://www.cpementalhealth.com/content/4/I/2

(C) 2008 Dell'Osso et al; licensee BioMed Central Ltd.

This is an Open Access article distributed under the terms of the Creative Commons Attribution License (http://creativecommons.org/licenses/by/2.0), which permits unrestricted use, distribution, and reproduction in any medium, provided the original work is properly cited.
Received: 9 November 2007

Accepted: 28 January 2008

\begin{abstract}
Background: DSM-IV identifies three stress response disorders (acute stress disorder (ASD), posttraumatic stress disorder (PTSD) and adjustment disorder (AD) that derive from specific life events. An additional condition of complicated grief (CG), well described in the literature, is triggered by bereavement. This paper reports on the reliability and validity of the Structured Clinical Interview for Trauma and Loss Spectrum (SCl-TALS) developed to assess the spectrum of stress response. The instrument is based on a spectrum model that emphasizes soft signs, low-grade symptoms, subthreshold syndromes, as well as temperamental and personality traits comprising clinical and subsyndromal manifestations.

Methods: Study participants, enrolled at 6 Italian Departments of Psychiatry located at six sites, included consecutive patients with PTSD, 44 with CG and a comparative group of 48 unselected controls.

Results: We showed good reliability and validity of the SCI-TALS. Domain scores were significantly higher in participants with PTSD or CG compared to controls. There were high correlations between specific SCl-TALS domains and corresponding scores on established measures of similar constructs. Participants endorsing grief and loss events reported similar scores on all instruments, except those with CG who scored significantly higher on the domain of grief reactions.
\end{abstract}


Conclusion: These findings provide strong support for the internal consistency, the discriminant validity and the reliability for the SCl-TALS. These results also support the existence of a specific grief-related condition and the proposal that different forms of stress response have similar manifestations.

\section{Introduction}

The Structured Clinical Interview for Trauma and Loss Spectrum (SCI-TALS) is an assessment instrument designed to quantify clinical features associated with the experience of stressful life events. DSM-IV [1] categorizes stress-related disorders as either acute stress disorder (ASD), post-traumatic stress disorder (PTSD) or adjustment disorder (AD). Both ASD and PTSD are specifically linked to highly dangerous and/or life-threatening experiences. By contrast, AD is defined by a range of low-level symptoms that occur in response to any life stress and persist for only a limited time. AD is widely regarded as a problematic diagnosis. Horowitz [2] proposed AD to be defined as a stress response syndrome, grouping it with the stress-related disorders in DSM.

There are no criteria in DSM-IV [1] for a syndrome specifically linked to difficult losses, yet a growing body of evidence strongly supports the occurrence of a bereavementrelated syndrome of complicated grief (CG) [3-6]. Intrusions, avoidance and failure to adapt also characterize this condition. Horowitz [2] further suggested that complicated grief could be considered a stress response syndrome. Given this way of thinking, stressful life events can be broadly categorized as those that entail experience of a threatening negative life event and those that entail loss of an important positive relationship or situation. We took this perspective in developing the SCI-TALS and designed it to include a spectrum of negative life events and losses and to assess responses that include intrusion, avoidance, emotionality and failure to adapt.

The SCI-TALS is one of a series of "spectrum" instruments that comprise a set of structured clinical interviews and self report questionnaires that evaluate the lifetime occurrence of isolated criterion and non-criterion symptoms, behavioral tendencies and temperament-like traits associated with a given DSM-IV disorder. In the spectrum model, subthreshold or atypical manifestations occur before, during or after onset of a full-blown DSM-IV disorder. Spectrum manifestations may comprise early onset precursors, prodromal features of onset or recurrence, or persistent residual symptoms, which interfere with overall functioning and quality of life. The extent of lifetime exposure to loss and threat events may comprise a risk factor for vulnerability to illness following an important life event. Lifetime symptom burden and/or existence of certain behavioral traits may contribute to the degree of impairment associated with a DSM-IV disorder. We believe that spectrum assessment can be useful for a range of clinical purposes, such as treatment selection, treatment outcome assessment, follow-up, and identifying subthreshold comorbidity [7-10]. We have developed and validated instruments for most of the DSM-IV disorders [11-18].

The purpose of this paper is to describe the SCI-TALS and to document its acceptability, reliability and validity. Data for the present report were collected between May 2004 and December 2005. The Ethics Committee of the Azienda Ospedaliera Universitaria of Pisa approved all recruitment and assessment procedures. Eligible subjects provided written informed consent, after receiving a complete description of the study and having the opportunity to ask questions. Subjects were not paid for their participation in accordance to the Italian laws for clinical studies.

\section{Methods Study Participants}

A consecutive group of 140 study participants was recruited, including 92 outpatients and inpatients, presenting for treatment at one of 6 Italian Departments of Psychiatry (Pisa, Cagliari, Milano, Napoli, Sassari and Siena), and 48 healthy controls. Eligible patients met DSM-IV-TR criteria for PTSD $(\mathrm{n}=48)$ [1] or complicated grief, determined by a score of at least 25 on the Inventory of Complicated Grief $(\mathrm{n}=44)$ [19]. Healthy controls $(\mathrm{n}=$ 48) were individuals without any history of psychiatric disorders presenting at the Departments of Ophthalmology of the local Universities for a routine sight control, and their friends and relatives. Individuals with severe medical illness, neurological diseases, substance abuse or psychotic symptoms in the month preceding the index assessment, or inability to participate because of the severity of psychiatric symptoms were excluded.

\section{Instruments and assessments}

The Structured Clinical Interview for DSM-IV axis-I disorders (SCID-I/P) [20] was used to determine DSM-IV diagnosis by psychiatrists trained and certified in the use of the study instruments at the Department of Psychiatry of the University of Pisa.

Participants completed the Inventory of Complicated Grief (ICG, translated into Italian by Dr. C. Carmassi and Dr. A. Fagiolini in March 2004) [19] to determine the presence of complicated grief, defined by a score of 25 or 
higher. The Italian translation was back-translated, revised and translated again.

The Impact of Event Scale (IES) [21] is a widely used scale that has excellent psychometric properties. This instrument assesses intrusion and avoidance symptoms that characterize stress response syndromes.

The Structured Clinical Interview for Trauma and Loss Spectrum [see Additional file 1] was developed by the authors, who comprise the Italian-American team of researchers belonging to the spectrum project. Originally developed in English, the interview was then translated into Italian, back translated, and revised for inconsistencies between the two languages. In the present study we used the final Italian version.

The SCI-TALS includes 116 items exploring the lifetime experience of a range of loss and/or traumatic events and lifetime symptoms, behaviors and personal characteristics that might represent manifestations and/or risk factors for the development of a stress response syndrome. The instrument is organized into 9 domains. Items responses are coded in a dichotomous way (yes/no) and domain scores are obtained by counting the number of positive answers.

Domain I (Items 1-10) catalogues a range of loss events, including death of a loved one, loss of an important relationship, loss of property, losses of physical functioning, or loss of social and economical status. Several authors have pointed to the fact that low magnitude events (e.g.: divorce, serious illness and financial reverses) may produce typical symptoms of traumatic stress, i.e. intrusion, avoidance and arousal [22-25]. In line with these studies, and with the spectrum concept, we included a range of severity of loss and trauma (Domain III) events as possible inciting events.

Domain II (Items 11-37) describes grief reactions that include a range of typical, atypical and sub-syndromal symptoms, related to the possible occurrence of complicated grief, conceptualized as a loss-specific stress response disorder. Loss specific items include longing, yearning and searching for the lost person or place, daydreams about what was lost, a need to reminisce, spending time with objects that are associated with the lost person or place, and frequent intense pangs of grief and sadness related to the loss. Stress response items include intrusions of recurrent upsetting images, avoidance of reminders of the loss, and failure to adapt (difficulty accepting the death, guilt or remorse, feeling life has no purpose and impairment in functioning). This domain also includes a section with 7 items targeting trait-like interpersonal functioning that might comprise a risk fac- tor for persistent grief. Examples include the need to be a caregiver, difficulty asking for help, and sensitivity to separation from loved ones.

Domain III (Items 38-58) lists events that range from DSM-IV qualifying traumas (e.g.: combat, natural disasters, sexual abuse, severe accidents) and "low-magnitude" events (e.g.: failures at school or at work, sexual harassment, abortion), that the patient might have experienced in his/her lifetime. Domain IV (Items 59-76) includes a range of emotional, physical and cognitive responses to loss and/or traumatic events identified in Domains I and III. Domain V (Items 77-85), Domain VI (Items 86-97) and Domain VIII (Items 106-110) include re-experiencing, avoidance and numbing, and arousal symptoms respectively. Domain VII (Items 98-105) targets maladaptive coping, and a last Domain (IX; Items 111-116) includes an experimental list of 6 personality traits that are not included in the analyses.

We evaluated the acceptability of the SCI-TALS using questions asking whether the interview was interesting, reassuring, distressing, and helpful for a better understanding of the disorder for either the patient or the physician. Items were rated on a $0-3$ scale, where $0=$ not at all, 1 = a little, 2 = much, 3 = very much.

\section{Statistical analyses}

We examined reliability of the SCI-TALS by analyzing correlations between domains and internal consistency of domains. Kuder-Richardson coefficient, a variant of the alpha coefficient for dichotomous items [26], was used to determine the internal consistency. Test-retest and interrater reliability of the SCI-TALS was performed at Pisa site only, by having different raters conduct a second SCITALS evaluation within 14 days of the initial assessment. We examined reliability using the infraclass correlation coefficient. Shrout criteria [27] were used to define the range of reliability: $0-0.10$ virtually none, $0.11-0.40$ slight, $0.41-0.60$ fair, $0.61-0.80$ moderate, $0.81-1$ substantial.

We examined the validity of the SCI-TALS by comparing mean domain scores among subjects with PTSD, CG and controls, using one-way analysis of variance followed by post-hoc comparisons with Dunnett's C-test, that allows for heterogeneity of variance between groups. The alpha level was corrected for multiple comparisons $(0.016=$ $0.05 / 3$ ). Analysis of covariance was performed to control for potential confounders such as age and gender. Comparisons of categorical variables across groups were conducted by using the $2 \times 3$ chi-square tests, followed by $2 \times$ 2 chi-square tests. Data analyses were carried out using SPSS 12.0.1. 
Table I: Demographic and clinical characteristics of the study samples

\begin{tabular}{|c|c|c|c|c|}
\hline & PTSD $N=48$ & $C G N=44$ & Controls $\mathrm{N}=48$ & Test, significance $(p)$ \\
\hline & Mean \pm S.D. & Mean \pm S.D. & Mean \pm S.D. & \\
\hline Age & $\begin{array}{c}44.8 \pm 14.3 \\
N(\%)\end{array}$ & $\begin{array}{c}49.3 \pm 14.5 \\
N(\%)\end{array}$ & $\begin{array}{c}41.2 \pm 12.2 \\
N(\%)\end{array}$ & $F=4.0, P<0.05, C G>C$ \\
\hline Female & $25(51.2)$ & $37(84.1)$ & $31(64.6)$ & Chi-square $=10.6, p<0.01, C G>P T S D$ \\
\hline Marital status & & & & Chi-square $=27.8, p<0.001$ \\
\hline Single & $14(29.2)$ & $12(27.3)$ & $23(47.9)$ & \\
\hline Married/living with partner & $32(66.7)$ & $18(40.9)$ & $24(50.0)$ & \\
\hline Widows-ers & I (2.I) & $12(27.3)$ & I (2.I) & \\
\hline$>8 \mathrm{y}$. of education & $32(66.7)$ & $24(54.5)$ & $38(79.2)$ & Chi-square $=6.3, p<0.05, C>C G$ \\
\hline \multirow[t]{2}{*}{ Employed full/part time } & $30(62.6)$ & $21(47.7)$ & $53(72.9)$ & Chi-square $=6.2, p=0.05, C>C G$ \\
\hline & Mean \pm S.D. & Mean \pm S.D. & Mean \pm S.D. & \\
\hline IES Total score & $26.1 \pm 17.2$ & $30.3 \pm 15.0$ & $12.0 \pm 11.8$ & $F=19.7, p<0.001 ; C G, P T S D>C$ \\
\hline Intrusive & $13.4 \pm 8.9$ & $16.0 \pm 8.5$ & $6.6 \pm 6.6$ & $F=16.8, p<0.001 ; C G, P T S D>C$ \\
\hline Avoidance & $12.8 \pm 9.4$ & $14.4 \pm 8.5$ & $5.4 \pm 5.7$ & $F=16.8, p<0.001, C G, P T S D>C$ \\
\hline ICG Total score & $9.3 \pm 7.1$ & $38.8 \pm 10.5$ & $5.1 \pm 6.5$ & $F=215.8, p<0.001, C G>P T S D, C$ \\
\hline
\end{tabular}

\section{Results}

\section{Demographic and Clinical Characteristics of Study Participants}

The study group characteristics are provided in Table 1. Controls were younger than CG patients. The majority of patients with CG $(84.1 \%)$ and of controls (64.6\%) were females, while patients with PTSD were equally distributed by gender. Patients with CG were more likely to be widowed than the other groups, had a lower educational level and were less likely to be employed than controls. As expected, CG patients had a significantly higher ICG total score compared to PTSD and controls (Table 1). Fifty percent of individuals with CG also met DSM-IV criteria for PTSD. Also as expected, both CG and PTSD participants scored higher on the IES than controls. Of the 48 PTSD participants, $48 \%$ met criteria for lifetime or current major depression, 33\% for panic disorder, $6.3 \%$ for generalized anxiety disorder, $6.3 \%$ for obsessive-compulsive disorder, $4.2 \%$ for bipolar II disorder, and 3\% for other disorders (including eating disorders or substance use disorder). Of the 44 CG participants, $75 \%$ met criteria for lifetime or current major depression, $22.7 \%$ for panic disorder, $9.1 \%$ for generalized anxiety disorder, $13.6 \%$ for bipolar II disorder, 5\% for other disorders (including alcohol use disorder, eating disorders or social anxiety disorder).

\section{Acceptability of the SCI-TALS}

The SCI-TALS was administered to patients and controls in one session of approximately 30 minutes. No one refused to participate and no participants failed to complete the interview. The acceptability of the interview was excellent: $96.9 \%$ of participants rated it as much or very much interesting, and nearly half (49.6\%) rated it as much or very much reassuring, $51.8 \%$ and $82.5 \%$ found that it was helpful to better understand the patients' own problems and to provide useful information to the physician, respectively. However, $32.8 \%$ of patients found the interview much or very much distressing.

\section{Reliability of the SCI-TALS}

We examined the internal consistency of the domains and correlations of domains in the pooled sample of individuals with either PTSD or CG diagnosis (Table 2). All Kuder-Richardson coefficients exceeded the minimum standard of 0.50 suggested for group comparison by Helmstadter [28]. Additionally, all domains and 12 out of 16 sub-domains exceeded the 0.70 standard for individual comparisons suggested by Nunnally [29]. For domains I, III and IX the internal consistency was not determined because these were checklists of events or of personality characteristics rather than symptoms. As reported in Table 3, correlations between domains were all positive and significant, with Pearson's $\mathrm{r}$ ranging between 0.46 and 0.76 ( $\mathrm{p}<0.01)$. Test-retest/inter-rater reliability was excellent, with infraclass correlation coeffi-

Table 2: Internal consistency (Kuder-Richardson coefficients) of the SCI-TALS Domains

\begin{tabular}{lcc}
\hline DOMAINS & \#ITEMS & KR-20 \\
\hline I - Loss events & 10 & $/$ \\
II - Grief reactions & 27 & 0.916 \\
III - Potentially traumatic events & 2 I & $/$ \\
IV - Reaction to losses or upsetting events & 18 & 0.863 \\
V - Re-experiencing & 9 & 0.809 \\
VI - Avoidance and Numbing & 1 I & 0.858 \\
VII - Maladaptive coping & 8 & 0.773 \\
VIII - Arousal & 6 & 0.789 \\
IX - Personal Characteristics-Risk Factors & 7 & $/$ \\
\end{tabular}


Table 3: Pearson's correlations between SCI-TALS Domains

\begin{tabular}{|c|c|c|c|c|c|}
\hline Domains & $\begin{array}{l}\text { IV Reaction to losses or } \\
\text { upsetting events }\end{array}$ & V Re-experiencing & $\begin{array}{l}\text { VI Avoidance and } \\
\text { Numbing }\end{array}$ & VII Maladaptive coping & VIII Arousal \\
\hline II - Grief reactions & $0.549 * *$ & $0.538 * *$ & $0.545^{* *}$ & $0.468 * *$ & $0.52 I^{* *}$ \\
\hline IV - Reaction to losses or upsetting events & & $0.709 * *$ & $0.710 * *$ & $0.535^{* *}$ & $0.722 * *$ \\
\hline$V-$ Re-experiencing & & & $0.762^{* *}$ & $0.528 * *$ & $0.706 * *$ \\
\hline$V I$ - Avoidance and Numbing & & & & $0.54 I * *$ & $0.676 * *$ \\
\hline VII - Maladaptive coping & & & & & $0.567^{* *}$ \\
\hline
\end{tabular}

$* * \mathrm{p}<0.01$

cients values exceeding .90 for each of the domains (Table $4)$.

\section{Validity of SCI-TALS}

Mean SCI-TALS domain scores for each of the groups are provided in Table 5, together with the results of the oneway ANOVA and the post-hoc pair wise comparisons. Not surprisingly, all participants reported experiencing similar lifetime rates of loss. Controls reported a mean of 3 lifetime losses, PTSD patients just under 4 and CG patients a mean of 4 . Given that CG patients were the oldest group, these slight differences are likely not meaningful. However differences in the response to loss are significant and meaningful. CG participants reported significantly greater levels (almost double) of grief reactions than either PTSD patients or controls. Interestingly, PTSD patients also reported grief reactions that were almost twice as great as controls. Also of note, the two patient groups did not differ on the remaining 6 Domains (Table 2), both scored significantly higher than controls on all Domains. Participants with CG endorsed fewer traumatic events than PTSD patients and more than controls. However CG patients' scores were not different from those with PTSD on any of the stress response domains.

Analysis of covariance was performed on the SCI-TALS domains to determine whether the differences between groups depended on gender and age imbalance. No asso-

Table 4: Test-retest and inter-rater reliability.

\begin{tabular}{lc}
\hline DOMAINS & $\begin{array}{c}\text { INTRACLASS CORRELATION } \\
\text { COEFFICIENT }\end{array}$ \\
\hline I - Loss events & .975 \\
II - Grief reactions & .992 \\
III - Potentially traumatic events & .974 \\
IV - Reaction to losses or & .981 \\
upsetting events & \\
V - Re-experiencing & .975 \\
VI - Avoidance and Numbing & .995 \\
VII - Maladaptive coping & .993 \\
VIII - Arousal & .972 \\
IX - Personal Characteristics-Risk & .969 \\
Factors & \\
\hline
\end{tabular}

ciation was found between age and the SCI-TALS domains. Gender was associated with the domains 'grief reactions', 'maladaptive copying' and 'arousal', but this association did not affect the differences among diagnostic groups.

\section{Discussion}

This paper introduces the Structured Clinical Interview for Trauma and Loss Spectrum (SCI-TALS), a new spectrum instrument focused on assessment of trauma and lossrelated experiences, acute event reactions and persistent symptoms and behavioral tendencies that occur in association with these stressful events. Results provide evidence for the reliability and validity of the SCI-TALS when administered to patients with post-traumatic stress disorder, complicated grief and normal controls. We found excellent inter-rater reliability of this interview when administered by different raters a mean of 2 weeks apart. As expected, patients who met DSM-IV criteria for PTSD and ICG criteria for complicated grief scored significantly higher than a comparison control group. This supports the validity of this instrument as a measure of trauma-loss spectrum.

We further believe that our results provide support for grouping stress response syndromes that describe responses to a range of difficult life events $[30,31]$. Such a grouping would include current DSM-IV diagnoses of ASD, PTSD and AD, as well as complicated grief. We did not include patients with DSM-IV adjustment or acute stress disorders in this study. However, results on both SCI-TAL and IES support the appropriateness of grouping CG and PTSD.

As far as we know, this is the first paper to directly compare individuals diagnoses with PTSD and those diagnosed with CG on the IES and other symptoms characteristic of the two disorders. Our results support the idea that there are strong commonalities in these two conditions. For example, scores on the IES are virtually identical. Prior studies of CG have shown, similar elevations on the IES $[5,6,32]$. Our results also indicate that CG and 
Table 5: SCI-TALS Domain total scores in the study samples

\begin{tabular}{|c|c|c|c|c|c|c|}
\hline DOMAINS & PTSD N = 48 & $C G N=44$ & Controls $\mathrm{N}=48$ & $\mathrm{~F}$ & $p$ & $\begin{array}{c}\text { Dunnett post Hoc comparison at } \\
\qquad p=0.016\end{array}$ \\
\hline & Mean \pm S.D. & Mean \pm S.D. & Mean \pm S.D. & & & \\
\hline I - Loss events & $3.77 \pm 1.87$ & $4.02 \pm 1.84$ & $2.83 \pm 1.26$ & 6.52 & $<.01$ & CG > controls \\
\hline II - Grief reactions & $6.42 \pm 5.13$ & $12.00 \pm 3.80$ & $3.23 \pm 3.21$ & 52.63 & $<.001$ & CG $>$ PTSD $>$ controls \\
\hline III - Potentially traumatic events & $5.06 \pm 3.07$ & $3.91 \pm 2.86$ & $2.25 \pm 1.85$ & 13.75 & $<.001$ & PTSD $>$ CG > controls \\
\hline IV - Reaction to losses or upsetting events & $10.27 \pm 3.50$ & $10.14 \pm 3.22$ & $3.62 \pm 3.04$ & 64.30 & $<.001$ & PTSD, CG > controls \\
\hline V-Re-experiencing & $5.10 \pm 2.35$ & $5.14 \pm 2.19$ & $1.17 \pm 1.36$ & 60.91 & $<.001$ & PTSD, CG > controls \\
\hline VI - Avoidance and numbing & $5.89 \pm 2.88$ & $5.70 \pm 2.72$ & $0.92 \pm 1.35$ & 64.97 & $<.001$ & PTSD, CG > controls \\
\hline VII - Maladaptive coping & $\mathrm{I} .44 \pm 1.76$ & $1.93 \pm 1.73$ & $0.17 \pm 0.43$ & 18.68 & $<.001$ & PTSD, CG > controls \\
\hline VIII - Arousal & $3.25 \pm 1.39$ & $3.36 \pm 1.51$ & $0.81 \pm 1.12$ & 54.07 & $<.001$ & PTSD, CG > controls \\
\hline
\end{tabular}

PTSD differ importantly with respect to key CG symptoms such as yearning and longing and sadness.

We also draw attention to the observation that nearly a third of the patients who participated in this study found the interview distressing. It is widely known that asking patients to talk about trauma and bereavement can be distressing. Although all still agreed to continue the interview, this reaction was not seen in our other spectrum projects, and should be noted. Clinicians conducting assessments of traumatized and bereaved individuals need to be cognizant of their sensitivity to activation around discussion of these issues.

We believe that this interview, like the other spectrum instruments we have developed, has the advantage of helping patients understand themselves and feel understood by their clinician. Moreover, lifetime spectrum symptoms of a range of mood and anxiety disorders were found to contribute to impairment [33,34], to represent a risk factor for suicidality [35], and to influence treatment outcome $[9,36,37]$.

We believe the spectrum approach provides a more specific description of the clinical features of each patient with potentially important implications for treatment choice and research. We also think that a less restrictive approach to the definition of the potentially traumatic events, than that defined in DSM-IV, would particularly help clinicians to explore more accurately post-traumatic stress conditions. Moreover, the evidence of a different profile for those suffering the consequences of trauma versus loss suggests that the spectrum approach might help identify specific phenotypes to be used in clinical, neurobiological and genetic studies. Further studies are warranted to assess the potential utility of this approach in clinical practice.

\section{Conclusion}

The present study documented the validity and reliability of a new spectrum assessment instrument, the Structured Clinical Interview for Trauma and Loss Spectrum (SCITALS). Domain scores were significantly higher in participants with PTSD or CG compared to controls and high correlations between specific SCI-TALS domains and corresponding scores on established measures of similar constructs were reported. Participants endorsing grief and loss events reported similar scores on all instruments, except those with CG who scored significantly higher on the domain of grief reactions, supporting the existence of a specific grief-related condition and the proposal that different forms of stress response have similar manifestations.

\section{Competing interests}

The author(s) declare that they have no competing interests.

\section{Authors' contributions}

LDO, KS, CCarm, PR, JDM, EF, JE and GBC participated to the SCI-TALS elaboration and development as part of the "Spectrum Project" research group. LDO, KS and CCarm conceived the study and participated in its design. LDO and CCarm coordinated the Multicenter national validation study from the Department of Psychiatry of the University of Pisa. CCarm, AC, NS, CConv and MC collected data from all patients recruited at the University of Pisa site. LL, CAA, BC, FP coordinated the data collection form the Universities of Sassari, Milan, Cagliari and Naples respectively. LDO, MKS and CCarm drafted the manuscript. PR participated in the design of the study and performed the statistical analysis. All authors read and approved the final manuscript. 


\section{Additional material}

\section{Additional file 1}

Structured Clinical Interview for Trauma and Loss Spectrum (SCITALS). The full text of the Structured Clinical Interview for Trauma and Loss Spectrum (SCI-TALS) is provided.

Click here for file

[http://www.biomedcentral.com/content/supplementary/17450179-4-2-S1.doc]

\section{References}

I. American Psychiatric Association: Diagnostic and Statistical Manual of Mental Disorders 4th edition. Washington DC: American Psychiatric Press; 1994.

2. Horowitz MJ, Siegel B, Holsen A, Bonanno GA, Milbrath C, Stinson $\mathrm{CH}$ : Diagnostic criteria for complicated grief disorder. $\mathrm{Am} J$ Psychiatry 1997, I 54:904-910.

3. Prigerson HG, Frank E, Kasl SV, Reynolds CF, Anderson B, Zubenko GS, Houck PR, George CJ, Kupfer DJ: Complicated grief and bereavement-related depression as distinct disorders: Preliminary empirical validation in elderly bereaved spouses. Am J Psychiatry 1995, I 52:22-30.

4. Prigerson HG, Shear MK, Jacobs SC, Reynolds CF, Maciejewski PK, Rosenheck R, Davidson JR, Pilkonis PA, Wortman CB, Williams JB, Widiger TA, Weiss R, Beery LC, Rynearson EK, Frank E, Kupfer DJ, Zisook S: Consensus criteria for traumatic grief: A rationale and preliminary empirical test. Br J Psychiatry 1999, I 74:67-73.

5. Shear MK, Shair H: Attachment, Loss, and Complicated Grief. Dev Psychobiol 2005, 47:253-267.

6. Shear MK, Smith-Caroff K: Traumatic loss and the syndrome of complicated grief. PTSD Research Quarterly 2002, I 3(I): I-8.

7. Cassano GB, Michelini S, Shear MK, Coli E, Maser JD, Frank E: The panic-agoraphobic spectrum: a descriptive approach to the assessment and treatment of subtle symptoms. Am J Psychiatry 1997, I 54(6):27-38.

8. Frank E, Cassano GB, Shear MK, Rotondo A, Dell'Osso L, Mauri M, Maser J, Grochocinski V: The spectrum model: A more coherent approach to the complexity of psychiatric symptomatology. CNS Spectrums 1998, 3:23-34.

9. Frank E, Cyranowski JM, Rucci P, Shear MK, Fagiolini A, Thase ME, Cassano GB, Grochocinski VJ, Kostelnik B, Kupfer DJ: Clinical significance of lifetime panic spectrum symptoms in the treatment of patients with bipolar I disorder. Arch Gen Psychiatry 2002, 59(I 0):905-II.

10. Cassano GB, Rucci P, Frank E, Fagiolini A, Dell'Osso L, Shear MK, Kupfer DJ: The mood spectrum in unipolar and bipolar disorder: Arguments for a unitary approach. Am J Psychiatry 2004, |61:1264-1269.

I I. Fagiolini A, Dell'Osso L, Pini S, Armani A, Bounani S, Rucci P, Cassano GB, Endicott J, Maser JD, Shear MK, Grochocinski VJ, Frank E: Validity and reliability of a new instrument for assessing mood symptomatology: the Structured Clinical Interview for Mood Spectrum (SCI-MOODS). Int J Methods Psychiatr Res 1999, 9:11-24.

12. Cassano GB, Banti S, Mauri M, Dell'Osso L, Miniati M, Maser JD, Shear MK, Frank E, Grochocinski VJ, Rucci P: Internal consistency and discriminant validity of the Structured Clinical Interview for Panic-Agoraphobic Spectru0m (SCI-PAS). Int J Methods Psychiatr Res 1999, 8:138-145.

13. Mauri M, Borri C, Baldassari S, Benvenuti A, Rucci P, Cassano GB, Shear MK, Grochocinski VJ, Maser JD, Frank E: Acceptability and psychometric properties of the Structured Clinical Interview for Anorexic-Bulimic Spectrum (SCI-ABS). Int J Methods Psychiatr Res 2000, 9:68-78.

14. Dell'Osso L, Cassano GB, Sarno N, Milanfreanchi A, Pfanner C, Gemignani A, Maser JD, Shear MK, Grochocinski VJ, Rucci P, Frank E: Validity and reliability of the Structured Clinical Interview for Obsessive-Compulsive Spectrum (SCI-OBS) and of the
Structured Clinical Interview for Social Phobia Spectrum (SCI-SHY). Int J Methods Psychiatr Res 2000, 9: | |-24.

15. Dell'Osso L, Rucci P, Cassano GB, Maser JD, Endicott J, Shear MK, Sarno N, Saettoni M, Grochocinski VJ, Frank E: Measuring social phobia and obsessive-compulsive disorders: Comparison of interviews and self-report instruments. Compr Psychiatry 2002, 43:8I-87.

16. Dell'Osso L, Armani A, Rucci P, Frank E, Fagiolini A, Corretti G, Shear MK, Grochocinski VJ, Maser JD, Endicott J, Cassano GB: Measuring mood spectrum: Comparison of interview (SCI-MOODS) and self-report (MOODS-SR) instrument. Compr Psychiatry 2002, 43:69-73.

17. Sbrana A, Dell'Osso L, Impagnatiello P, Doria MR, Spagnoli S, Ravani L, Cassano GB, Frank E, Shear MK, Grochocinki VJ, Rucci P, Maser JD, Endicott J: Acceptability, validity and reliability of the Structured Clinical Interview for the Spectrum of Substance Use (SCI-SUBS): a pilot study. Int $\int$ Methods Psychiatr Res 2003, I 2(2): I05-I| 5 .

18. Sbrana A, Dell'Osso L, Benvenuti A, Rucci P, Cassano P, Banti S, Gonnelli C, Doria MR, Ravani L, Spagnoli S, Rossi L, Raimondi F, Catena M, Endicott J, Frank E, Kupfer DJ, Cassano GB: The psychotic spectrum: validity and reliability of the Structured Clinical Interview for the Psychotic Spectrum. Schizophr Res 2005, 75:375-387.

19. Prigerson HG, Maciejewski PK, Reynolds CF, Bierhals AJ, Newsom JT, Fasiczka A, Frank E, Doman J, Miller M: Inventory of Complicated Grief: a scale to measure maladaptive symptoms of loss. Psychiatry Res 1995, 59(I-2):65-79.

20. First MB, Spitzer RL, Williams JBW, Gibbon M: Structured Clinical Interview for DSM-IV-Patient Edition (SCID-P) Washington DC: American Psychiatric Press; 1995.

21. Horowitz M, Wilner N, Alvarez W: Impact of Event Scale: a measure of subjective stress. Psychosom Med 1979, 4 I (3):209-18.

22. Breslau N, Davis G: Post traumatic stress disorder: the stressor criterion. J Nerv Ment Dis 1987, I 75:255-264.

23. Solomon SD, Canino G: The appropriateness of DSM-III-R criteria for posttraumatic stress disorder. Compr Psychiatry 1990, 3 I :227-237.

24. Galea S, Resnick H: Posttraumatic stress disorder in the general population after mass terrorist incidents: considerations about the nature of exposure. CNS Spectr 2005, I 0(2): I07-I 5.

25. Moreau C, Zisook S: Rationale for a post-traumatic stress spectrum disorder. Child Adolesc Psychiatr Clin N Am 2002, 25(4):775-790.

26. Nunnally J, Bemstein IH: Psychometric Theory 3rd edition. New York: McGraw-Hill; 1994.

27. Shrout PE: Measurement reliability and agreement in psychiatry. Stat Methods Med Res 1998, 7(3):301-317.

28. Helmstadter GC: Principles of Psychological Measurements New York: Appleton-Century-Crofts Inc; 1964.

29. Nunnally JC: Psychometric Theory 2nd edition. New York: McGrawHill; 1978.

30. Breslau N, Reboussin BA, Anthony JC, Storr CL: The structure of posttraumatic stress disorder: latent class analysis in 2 community samples. Arch Gen Psychiatry 2005, 62(I 2): | 343-5 I.

31. Maercker A, Einsle F, Köllner V: Adjustment Disorders as Stress Response Syndromes: A New Diagnostic Concept and Its Exploration in a Medical Sample. Psychopathology 2007, 40:135-146.

32. Langner R, Maercker A: J Complicated grief as a stress response disorder: evaluating diagnostic criteria in a German sample. Psychosom Res 2005, 5:235-242.

33. Langner $\mathrm{R}$, Maercker A: Complicated grief as a stress response disorder: evaluating diagnostic criteria in a German sample. J Psychosom Res 2005, 5:235-242.

34. Bazzichi L, Maser J, Piccinni A, Rucci P, Del Debbio A, Vivarelli L, Catena M, Bouanani S, Merlini G, Bombardieri S, Dell'Osso L: Quality of life in rheumatoid arthritis: impact of disability and lifetime depressive spectrum symptomatology. Clin Exp Rheumatol 2005, 23(6):783-8.

35. Fagiolini A, Kupfer DJ, Masalehdan A, Scott J, Houck P, Frank E: Functional impairment in the remission phase of bipolar disorder. Bipolar Disord 2005, 7:281-285.

36. Balestrieri M, Rucci P, Sbrana A, Ravani L, Benvenuti A, Gonnelli C, Dell'Osso L, Cassano GB: Lifetime rhythmicity and mania as 
correlates of suicidal ideation and attempts in mood disorders. Compr Psychiatry 2006, 47(5):334-4I.

37. Frank E, Shear MK, Rucci P, Cyranowski JM, Endicott J, Fagiolini A, Grochocinski VJ, Houck P, Kupfer DJ, Maser JD, Cassano GB: Influence of panic-agoraphobic spectrum symptoms on treatment response in patients with recurrent major depression. Am J Psychiatry 2000, 157:1 I0I-I 107.

Publish with Biomed Central and every scientist can read your work free of charge

"BioMed Central will be the most significant development for disseminating the results of biomedical research in our lifetime. " Sir Paul Nurse, Cancer Research UK

Your research papers will be:

- available free of charge to the entire biomedical community

- peer reviewed and published immediately upon acceptance

- cited in PubMed and archived on PubMed Central

- yours - you keep the copyright

Submit your manuscript here:

http://www.biomedcentral.com/info/publishing_adv.asp 